\title{
Individual Behavioral Reactions in the Context of Food Sensitivities in Children with Attention-Deficit/Hyperactivity Disorder before and after an Oligoantigenic Diet
}

\author{
Elena Yorgidis ${ }^{\dagger}{ }^{\oplus}$, Lisa Beiner ${ }^{\dagger}$, Nicola Blazynski ${ }^{\dagger}$, Katja Schneider-Momm, Hans-Willi Clement, \\ Reinhold Rauh $(\mathbb{D}$, Eberhard Schulz, Christina Clement $* \ddagger$ and Christian Fleischhaker $* \neq \mp(\mathbb{D}$
}

Citation: Yorgidis, E.; Beiner, L.; Blazynski, N.; Schneider-Momm, K.; Clement, H.-W.; Rauh, R.; Schulz, E.; Clement, C.; Fleischhaker, C. Individual Behavioral Reactions in the Context of Food Sensitivities in Children with Attention-Deficit/ Hyperactivity Disorder before and after an Oligoantigenic Diet. Nutrients 2021, 13, 2598. https://doi.org/ $10.3390 /$ nu13082598

Academic Editor: Roser Granero

Received: 23 June 2021

Accepted: 26 July 2021

Published: 28 July 2021

Publisher's Note: MDPI stays neutral with regard to jurisdictional claims in published maps and institutional affiliations.

Copyright: (c) 2021 by the authors. Licensee MDPI, Basel, Switzerland. This article is an open access article distributed under the terms and conditions of the Creative Commons Attribution (CC BY) license (https:/ / creativecommons.org/licenses/by/ $4.0 /)$.
Department of Child and Adolescent Psychiatry, Psychotherapy and Psychosomatics, Faculty of Medicine, Medical Center-University of Freiburg, D-79104 Freiburg, Germany; elena.yorgidis@gmx.de (E.Y.); lisa.beiner@uniklinik-freiburg.de (L.B.); n.blazynski@gmail.com (N.B.);

katja.schneider-momm@uniklinik-freiburg.de (K.S.-M.); hans-willi.clement@uniklinik-freiburg.de (H.-W.C.); reinhold.rauh@uniklinik-freiburg.de (R.R.); profeberhardschulz@gmx.de (E.S.)

* Correspondence: christina.clement@uniklinik-freiburg.de (C.C.);

christian.fleischhaker@uniklinik-freiburg.de (C.F.); Tel.: +49-761-270-68620 (C.F.); Fax: +49-761-270-69490 (C.F.)

+ The authors contributed equally to this work.

$\ddagger$ These authors share senior authorship.

Abstract: The influence of food intake on behavior problems of children with Attention-Deficit/ Hyperactivity Disorder (ADHD) was already described in the early 20th century. Eliminating food components by using the Oligoantigenic Diet (OD) leads to reduction of ADHD symptoms for more than two-thirds of patients. The aim of our study was to reveal how to identify foods having an impact on ADHD symptomatology. Therefore, 28 children with ADHD participating in this uncontrolled, open trial were examined before and after a restricted elimination diet. They kept a daily $24-\mathrm{h}$ recall nutrition and behavior journal and filled out the abbreviated Conners' scale (ACS) to identify foods which increased ADHD symptoms. The study was completed by 16 children $(13 \mathrm{~m} / 3 \mathrm{f})$. After four weeks of elimination diet the individual food sensitivities were identified in a reintroduction phase. A repetitive increase of ADHD symptoms by at least two points in ACS after food introduction hints at food sensitivity. Twenty-seven food sensitivity reactions were identified. Most of the participants were sensitive to more than one food. Food intolerances could not be identified without preceding OD. The combination of OD and subsequent food challenge appears as a valid method to identify individual food sensitivity in ADHD.

Keywords: adolescents; attention-deficit/hyperactivity disorder; behavior; child; diet; elimination; food intolerance; nutrition; Oligoantigenic Diet

\section{Introduction}

With a worldwide prevalence of 5.3\% among children and adolescents, AttentionDeficit/Hyperactivity Disorder (ADHD) is the most common behavioral disorder [1,2]. ADHD occurs across cultures in about $5 \%$ of children and about $2.5 \%$ of adults. In children there is a gender related ratio of 2:1 (male: female), [3]. The mechanisms triggering ADHD have not yet been fully identified. Genetic predisposition and pre-, peri- and postnatal environmental influences play a decisive role as do multiple interacting factors [4-6]. Nutrition also plays a role in the development of ADHD [7]. Previous study results have supported the theory that ADHD is an expression of a genetically determined neurodevelopmental disorder. Depending on the degree of severity, the guidelines recommend different treatment options, including parent training, behavioral therapy, pharmacotherapy, and dietary interventions [8-10].

As early as 1922, Shannon noted an increase in restlessness and sleep disorder in children in association with food allergies. After eliminating foods such as tomatoes, eggs 
and grains, there was reduction or even disappearance of ADHD symptoms [10]. In 1983, Egger et al. were the first to carry out the Oligoantigenic Diet (OD) - as a dietary diagnostic method to identify food allergies in the field of allergology-in the context of ADHD. Foodstuffs during diet were consciously reduced to very few hypoallergenic foods. The choice of food was initially kept to a minimum. Approved foods were hypoallergenic, mainly including foods which rarely caused adverse reactions. Throughout the OD the ADHD patients showed significant improvements: of 76 participants in this study, 62 children reduced their symptoms. Furthermore, 21 patients no longer met diagnostic criteria for ADHD. Most children responded to two to seven different foods. Re-exposure to the foods caused reappearance or intensified symptoms of ADHD [11]. A study by Pelsser et al. (2009) also showed a reduction in ADHD symptoms after an OD. Here $60 \%$ of the participants showed a reduction in symptoms of at least 50\% measured with the ADHD Rating Scale [12].

Since then, further studies have shown that nutrition is a strong mediator and/or moderator of ADHD symptoms [8-22]. Dietary interventions in ADHD including elimination diets have shown highly significant effects [13-15,17-22] with effect sizes up to Cohen's $d=5.0$ in unblinded studies [7].

Severe dietary interventions such as restricted elimination diets do have a clear impact on daily life and therefore cannot be kept under blinded conditions. In order to minimize the various biases which influence the assessment of ADHD symptoms, Dölp et al. [22] used blinded video ratings to evaluate their primary outcome diagnostic tool, ARS, in the context of dietary intervention. The results showed hardly any difference between blinded and unblinded ratings. Dölp et al. found that OD can lead to symptom reductions in food sensitive children and adolescents with ADHD. After 4 weeks of diet, approximately $60 \%$ of the patients showed significant improvement in their condition in ARS [22].

The objective of the present study is to answer the following questions: is it possible to identify foods that intensify typical ADHD symptoms in children by applying OD? Do the participants show different reactions to the same food? Can individual food sensitivities already be identified in a pre-diet phase? Can strong leads to later diagnosed food sensitivities be seen already in the anamnesis?

\section{Materials and Methods}

The study was approved by the Ethics Committee of Freiburg (application number 111/14) in accordance with the World Medical Association's Declaration of Helsinki. Patients and parents gave written informed consent before participating in the study.

\subsection{Participants}

The study took place at the Department of Child and Adolescent Psychiatry, Psychotherapy and Psychosomatics of the Medical Center, University of Freiburg. Psychotherapists and general practitioners informed their patients about the study. They were then recruited by study staff. Some participants also became aware of the study via the local press or information on the Internet. Families did not receive any reward for their collaboration in the study.

Interested participants were instructed in detail on the procedure of the study, either in group meetings or individually. ADHD diagnoses were confirmed with Kiddie-SADSPresent and Lifetime Version (K-SADS-PL) [23]. Table 1 shows the characteristics of the participants.

Four of the participants (25\%) had a disease at the beginning of the study (rhinitis $(n=2)$, influenza $(n=1)$, gastroenteritis $(n=1))$. 
Table 1. Participants' characteristics.

$\begin{array}{cc}\text { Included }(n) & 16 \text { out of } 28 \\ \text { Age (means } \pm \mathrm{SD}(\text { range })) & 9.25 \pm 1.73(7-13) \\ \text { Gender }(\mathrm{m} / \mathrm{f}) & 13 / 3 \\ \text { Subtypes } \mathrm{c} / \mathrm{hi} / \mathrm{i}(n=28) & 16 / 10 / 2 \\ \text { Responder }(n=16) & 9 / / 6 / 1 \\ & \text { Dyslexia }(\mathrm{F} 81.0, n=6) \\ \text { Comorbidity } & \text { Dyscalculia }(\mathrm{F} 81.2, n=2) \\ & \text { Oppositional Defiant Disorder }(\mathrm{F} 91.3, \mathrm{~F} 91.8, n=2) \\ & \text { Autism (F84.0, } n=2) \text { diagnosed in the course of the study } \\ \text { Encopresis }(\mathrm{F} 98.1, n=1)\end{array}$

Subtypes: c: combined type; hi: predominantly hyperactive/impulsive; i: predominantly inattentive.

\subsection{Inclusion and Exclusion Criteria}

Children and adolescents between the age of 7 and 18 attending at least 2nd grade of a general education school with a confirmed ADHD diagnosis according to the criteria of ICD10 were included in the study. Children and their parents had to sign for informed consent.

Exclusion criteria were severe concomitant disease, neurological or organic comorbidities which cannot be subjected to dietary intervention. Patients could not participate if there was a lack of compliance either of the parents or children, or a lack of reading or writing skills. Concurrent drug therapy of ADHD or participation in other studies at the same time was not allowed. Children were not to be included when following a special diet (e.g., vegetarian, vegan).

\subsection{Measures}

The primary outcome was measured using the ADHD rating scale IV (ARS) that is frequently used in ADHD trials [24-34].

\subsection{Anamnesis Concerning Food Sensitivity and Allergies in the Beginning}

Participants were asked about existing food intolerances, such as allergic reactions to foodstuff or diagnosed food intolerances such as malabsorption or enzyme deficiency.

In the special dietary anamnesis, the children were asked about their preferences and aversions to certain foods.

\subsection{Conners' Rating Scale}

To assess daily changes of behavior more precisely, the abbreviated Conners' scale (ACS) was used on a daily basis $[15,35,36]$. In addition to diagnostics, the Conners' scales are important for treatment planning, monitoring, and therapy evaluation. The ACS used here is derived from the long version (105 items), the Conners $3^{\circledR}$. This is composed of the items that achieved the highest scores in patients with ADHD and which react very sensitively to therapy effects. Therefore, they are suitable as a short-term follow-up and therapy evaluation [35]. It consists of ten selected items. The ten items are: (1) restless and overactive; (2) excitable impulsive; (3) disturbs other children; (4) fails to finish thingsshort attention span; (5) constantly fidgeting; (6) inattentive, easily distracted; (7) demands must be met immediately - easily frustrated, (8) cries often and easily; (9) mood changes quickly and drastically (10) temper outbursts, explosive and unpredictable behavior.

Each item was assessed on a 4-point rating scale which resulted in a total score ranging from 0 to 3 . With a time requirement of about five minutes, the ACS is a suitable instrument for daily progress monitoring or therapy evaluation. [36].

\subsection{Nutrition and Behavior Diary}

The nutrition and behavior diary, developed for this study, is based on the allergy diary described by Körner and Schareina [35]. It was kept daily as a 24-h recall protocol by the parents and/or children during the entire study in order to be able to track a 
temporal and causal relationship between the foods consumed and the occurring ADHD symptoms [34].

Leisure activities that may also affect ACS are also reported e.g., birthday parties, physical training, circus events, and school hiking days.

\subsection{Procedure}

Initial examination, verifying the ADHD diagnosis, and an assessment of medical health status was followed by a one-week retrospective ADHD rating scale IV [24]. T0 was considered baseline. Figure 1 shows the timeline of the study.

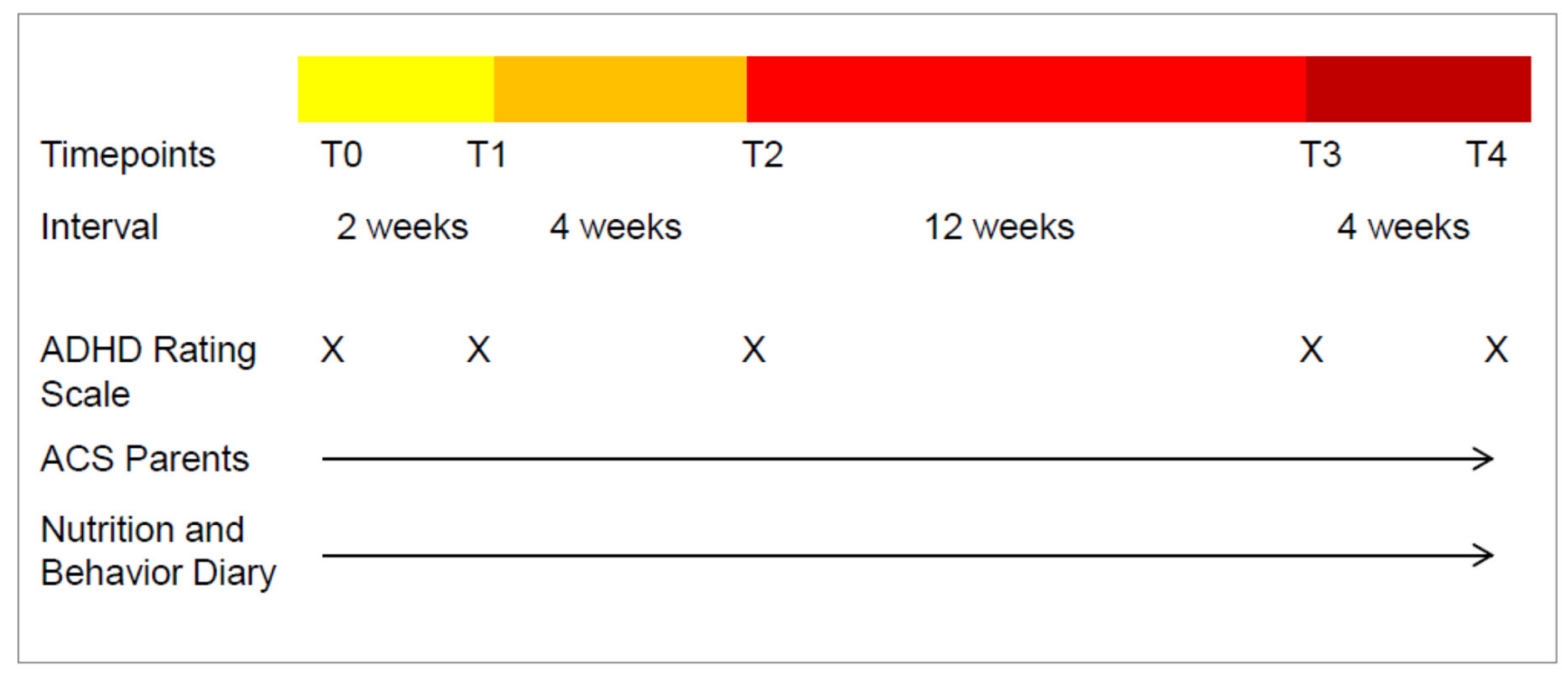

Figure 1. Timescales and measures for each appointment. Yellow bar: pre-diet phase, no change in everyday food intake; Orange bar: diet phase OD; Red bars: food challenge phase, testing the different main food groups. T0: physical examination, Baseline ARS; T1: physical examination, ARS; T2: physical examination, ARS; T3: physical examination, ARS; T4: physical examination, ARS, individual dietary recommendations.

Between T0 and T4, parent ACS and 24-h nutrition and behavior protocols were kept daily. Participants were asked to keep their daily eating habits.

From T1-T2 the children and their families are in a 4-week period of OD. During the diet phase, only a limited selection of hypoallergenic food was allowed to be eaten. The structure of this diet was based on the protocol of Egger et al. and Pelsser et al. [11,14]. Supplementation of vitamins and minerals was advised.

At all time-points, physical examination was kept by a medical professional. At T0, the physical condition and basic neurological findings were additionally recorded.

Throughout the study the families were advised by a nutritionist in order to avoid the risk of malnutrition and to facilitate the implementation of the diet.

All children with an improvement of at least $40 \%$ in the ARS total between T1 and T2 were considered to be responders [14].

During T2-T4 the reintroduction of usually consumed foods was proceeded at a time interval of 3-4 days testing each food. ACS questionnaire was completed daily and the nutrition and behavior diary was maintained.

Food sensitivities were defined for foods that showed a repetitive increase in symptoms of at least 2 points on the ACS scale after ingestion compared to the three days before baseline. After identifying the intolerant food in the reintroduction phase, it was assessed whether the intolerant food was consumed before the diet.

\subsection{Statistics}

The data of 16 participants (out of 28) that completed the whole study was included in statistical analysis. 
In cases in which subsamples exceeded five observations, $t$-tests were performed to compare ACS values on the day of reintroduction (dE0), and one, two or three days after reintroduction $(\mathrm{dE}+1, \mathrm{dE}+2, \mathrm{dE}+3$, etc.) of a particular food to the values one day before reintroduction $(\mathrm{dE}-1)$. All subsamples were too small to apply more complex statistical analyses such as ANOVA with repeated measurements. All statistical analyses were performed with SPSS version 23.0 (IBM Corporation, Armonk, NY, USA).

\section{Results}

\subsection{Participants}

16 out of 28 children and adolescents completed the study. The proportion by gender corresponds to the general prevalence of ADHD worldwide. We had $81 \%$ male and $19 \%$ female participants in our study.

During the diet phase 12 participants either dropped out $(n=2)$ of the study at their own request or were considered non-responders $(n=10)$. None of the participants had medical treatment for ADHD during the whole study (Table 2).

Table 2. Characteristics of dropped out participants.

\begin{tabular}{cc}
\hline Dropped out $(n)$ & 12 out of 28 \\
Age $($ means \pm SD (range) $)$ & $10.5 \pm 1.86(8-14)$ \\
Gender $(\mathrm{m} / \mathrm{f})$ & $9 / 3$ \\
\hline
\end{tabular}

\subsection{ADHD Symptoms According to ARS}

The results of this study show that, under careful supervision, children can maintain a 4 weeks OD as documented in the nutrition and health diary. Reductions in ADHD symptoms of $40 \%$ or more were seen in 17 participants.

At $\mathrm{T} 0$, the 28 ARS parent ratings yielded $\mathrm{M}=30.36$ and $\mathrm{SD}=8.87$. Figure 2 shows the individual ARS total score trajectories from T0 to T2.

After 2 weeks (T1) of continuing usual nutrition behavior, parental ARS was not significantly different to $\mathrm{T} 0$ (T0: $\mathrm{M}=30.36, \mathrm{SD}=8.87 ; \mathrm{T} 1: \mathrm{M}=29.54, \mathrm{SD}=9.64 ; F(1,27)<1$ ).

From the 28 participants starting the diet, $26(91.6 \%)$ completed. As shown in Figure 2A, after 4 weeks of OD (T2) we observed a significant reduction of ARS total score (T2: $\mathrm{M}=15.62, \mathrm{SD}=8.05, F(1,25)=112.34, p<0.0001)$. The percentage of improvement observed after the diet, according to the change in ARS total score, was $47.4 \%$ on average, ranging from $3.3 \%$ to $81.8 \%$. Nine children showed at least $40 \%$ symptom reductions in both ARS subscales of inattention and hyperactivity/impulsivity. Thirteen children showed at least a $40 \%$ reduction in one subscale. Only three of the participants did not respond in either subscale.

According to Storebø et al. [27] a change of 6.6 points on the ARS is considered as the minimum for a clinically relevant difference. 22 of the 26 participants $(84 \%)$ showed improvements of between 9 and 27 points between T1 and T2. Three of the 26 participants (11\%) showed improvements of between 9 and 13 points between $\mathrm{T} 0$ and $\mathrm{T} 1$. 

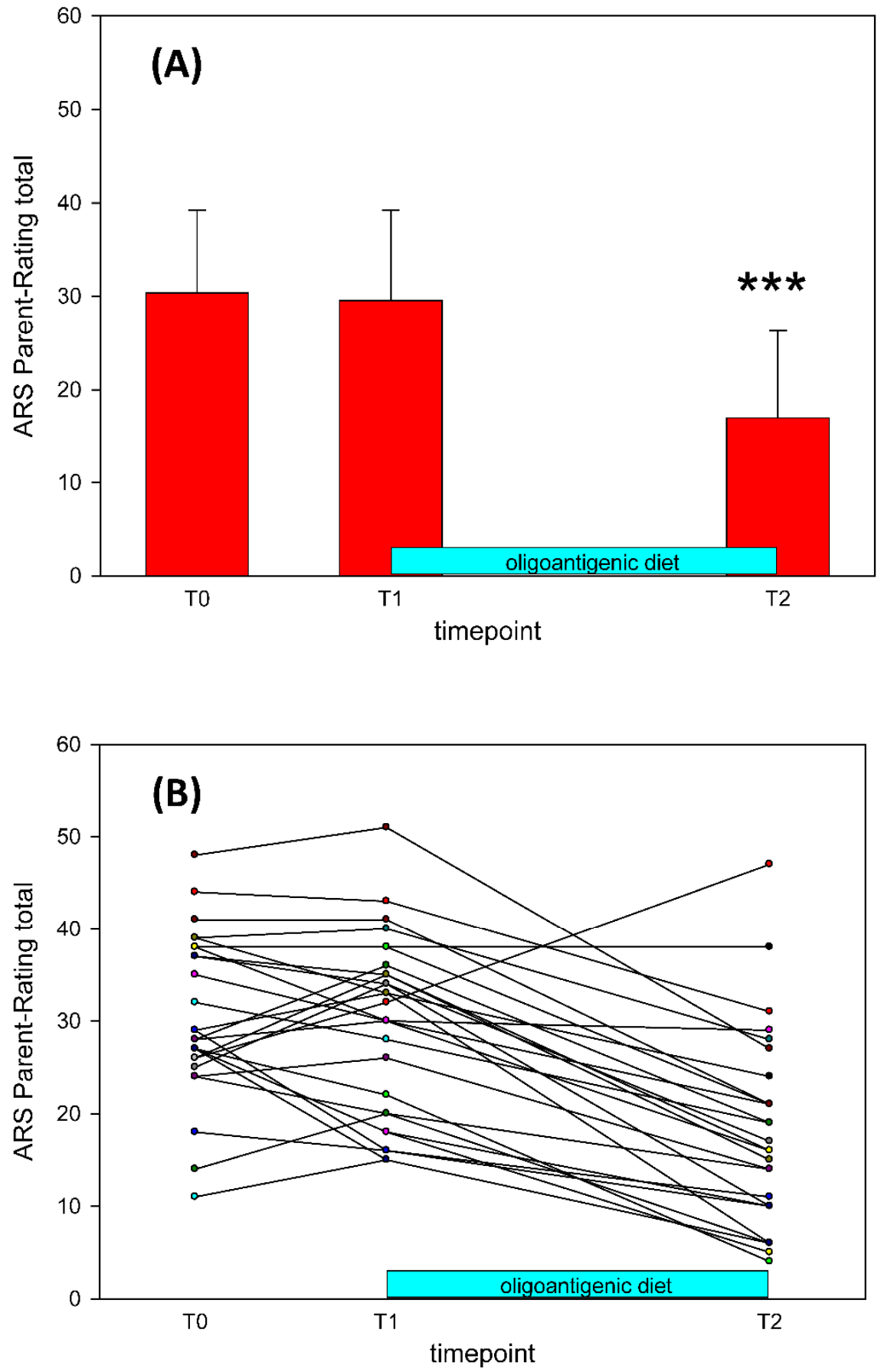

Figure 2. (A) Average changes in all participants $(n=28)$ of the ARS scores at each time point (means $\pm \mathrm{SD}$ ), $p<0.001^{* * *}$ (ANOVA with repeated measurements). (B) ADHD Rating Scale total scale for all participants in the study. $n=28$, T0: Baseline, T1: Start of the OD, T2: End of the OD.

\subsection{Identified Food Sensitivity}

The statistical analysis of the reintroduction phase showed 27 different types of food sensitivity (see Figure 3). 


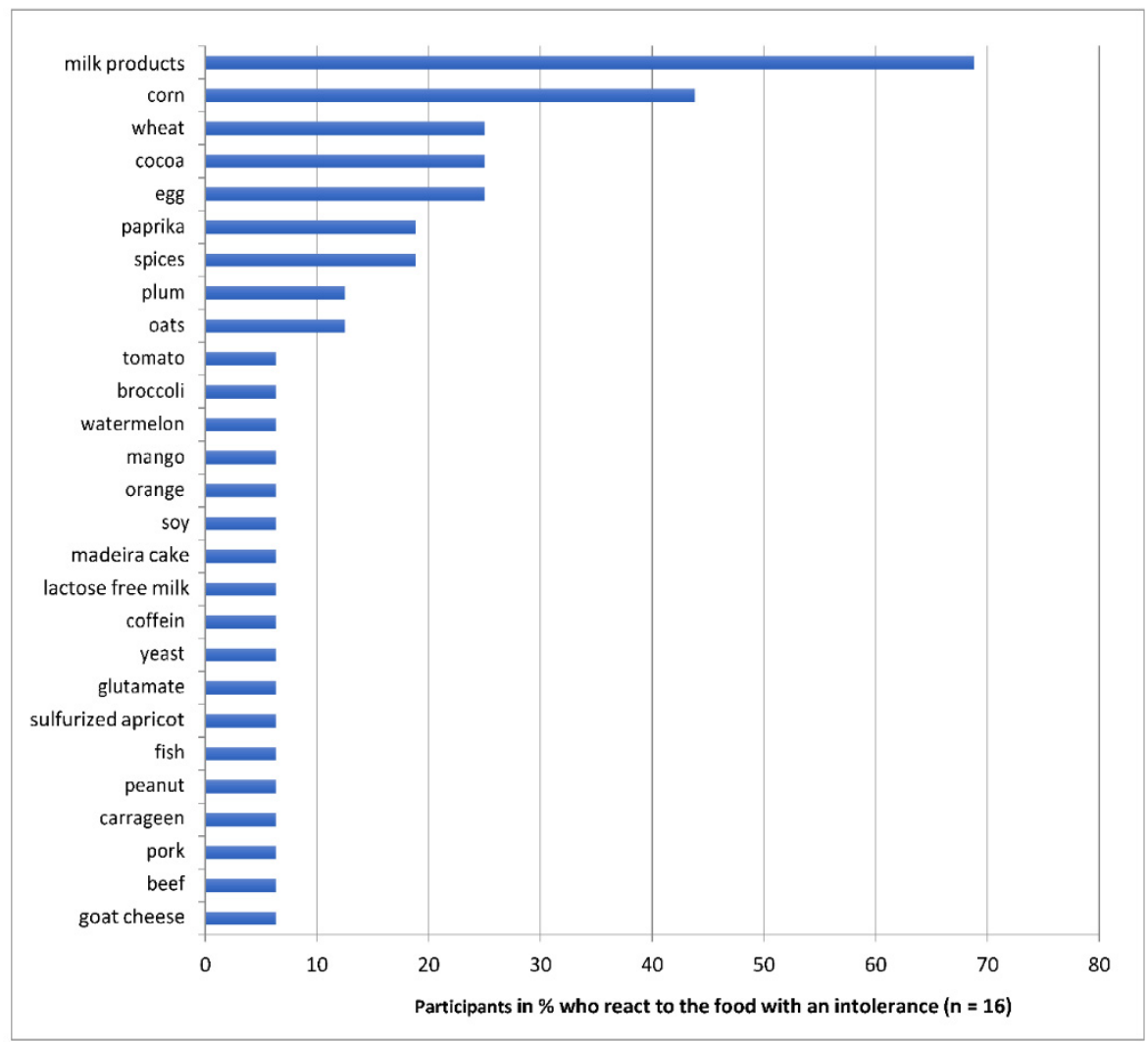

Figure 3. Identified food sensitivities during the study: Percentages of children $(n=16)$ reacting to the respective food with an increase in ADHD symptoms.

\subsection{Reactions to Intolerant Food after the $O D$}

Each responder to the OD showed individual food sensitivity, reacting to between 1-10 different foods in the food challenge phase. The three most common detected sensitivities are listed below as examples.

\subsubsection{Example 1: Milk Products}

The group of dairy consisted of milk, yoghurt, curd cheese, cream, cheese and butter made from cow's milk. Lactose-free products and products made from sheep's or goat's milk were not included.

A total of $68.8 \%(n=11)$ of respondents showed a change in ACS after taking dairy products. Among the foods tested, milk products are the ones that most often lead to an increase in ACS levels.

On average, the analysis shows a significant increase in ACS on days $\mathrm{dE}+1, \mathrm{dE}+2$ and $\mathrm{dE}+3$ with a sustained effect observed for three days.

Evaluating the milk products, we found two differently reacting groups as shown in Figure 4 . Group $1(n=5)$ initially responded to the intake of milk products with a decrease in ACS followed by a significant increase in the ACS rating after 1 day. In contrast, group 2 $(n=6)$ showed a significant increase in the ACS rating on the day of consumption of dairy. 

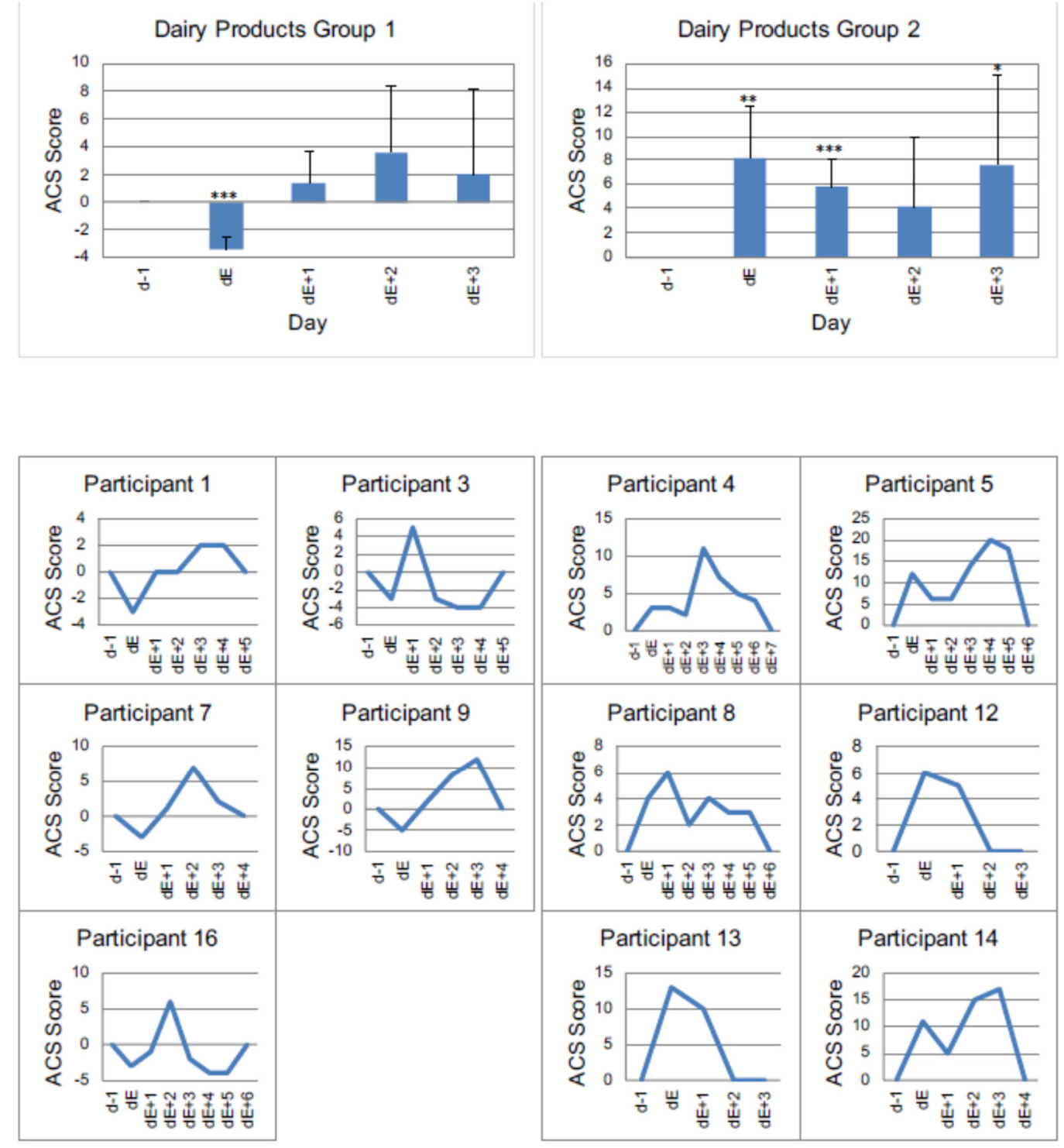

Figure 4. Individual reactions of participants to dairy products, measured by ACS. Group 1 (participants with a decrease of value in ACS at day of reintroduction) vs. Group 2 (participants with an increase of value in ACS at the day of reintroduction) $p<0.05^{*}, p<0.01^{* *}, p<0.001^{* * *}$ (one sided $t$-test). $\mathrm{dE}-1$ : day before reintroduction, dE: day of reintroduction, $\mathrm{dE}+1$ : day 1 after reintroduction etc.

Figure 4, Tables 3 and 4 show the daily courses of the mean values as well as the standard deviations of all children in the respective groups. In addition, the individual time courses of each child are displayed.

Table 3. Means and standard deviations of behavioral reactions to dairy products of Group $1(n=5)$.

\begin{tabular}{ccccc}
\hline Day & M & SD & $\boldsymbol{t ( 4 )}$ & $p$ \\
\hline $\mathrm{dE}$ & -3.40 & 0.89 & -8.50 & 0.001 \\
$\mathrm{dE}+1$ & 1.40 & 2.30 & 1.36 & 0.246 \\
$\mathrm{dE}+2$ & 3.60 & 4.83 & 1.67 & 0.171 \\
$\mathrm{dE}+3$ & 2.00 & 6.16 & 0.73 & 0.508 \\
\hline
\end{tabular}


Table 4. Means and standard deviations of intolerance reactions to dairy products of Group $2(n=6)$.

\begin{tabular}{ccccc}
\hline Day & M & SD & $\boldsymbol{t ( 5 )}$ & $p$ \\
\hline $\mathrm{dE}$ & 8.17 & 4.36 & 4.59 & 0.006 \\
$\mathrm{dE}+1$ & 5.83 & 2.32 & 6.17 & 0.002 \\
$\mathrm{dE}+2$ & 4.17 & 5.74 & 1.78 & 0.136 \\
$\mathrm{dE}+3$ & 7.67 & 7.34 & 2.56 & 0.051 \\
\hline
\end{tabular}

\subsubsection{Example 2: Corn}

Figure 5, Tables 5 and 6 show the behavioral reactions to corn.

In total, seven children (43.8\%) responded to the intake of products containing corn, as shown in Figure 5.

Group 1 shows a decrease in the ACS value on the day of corn introduction, the largest increase (11 points) on day $\mathrm{dE}+1$ and a value of 0 on day $\mathrm{dE}+3$.

Group 2 shows an ACS value increase directly on the day the corn is taken. This is significant on day $\mathrm{dE}+1$ and $\mathrm{dE}+2$.
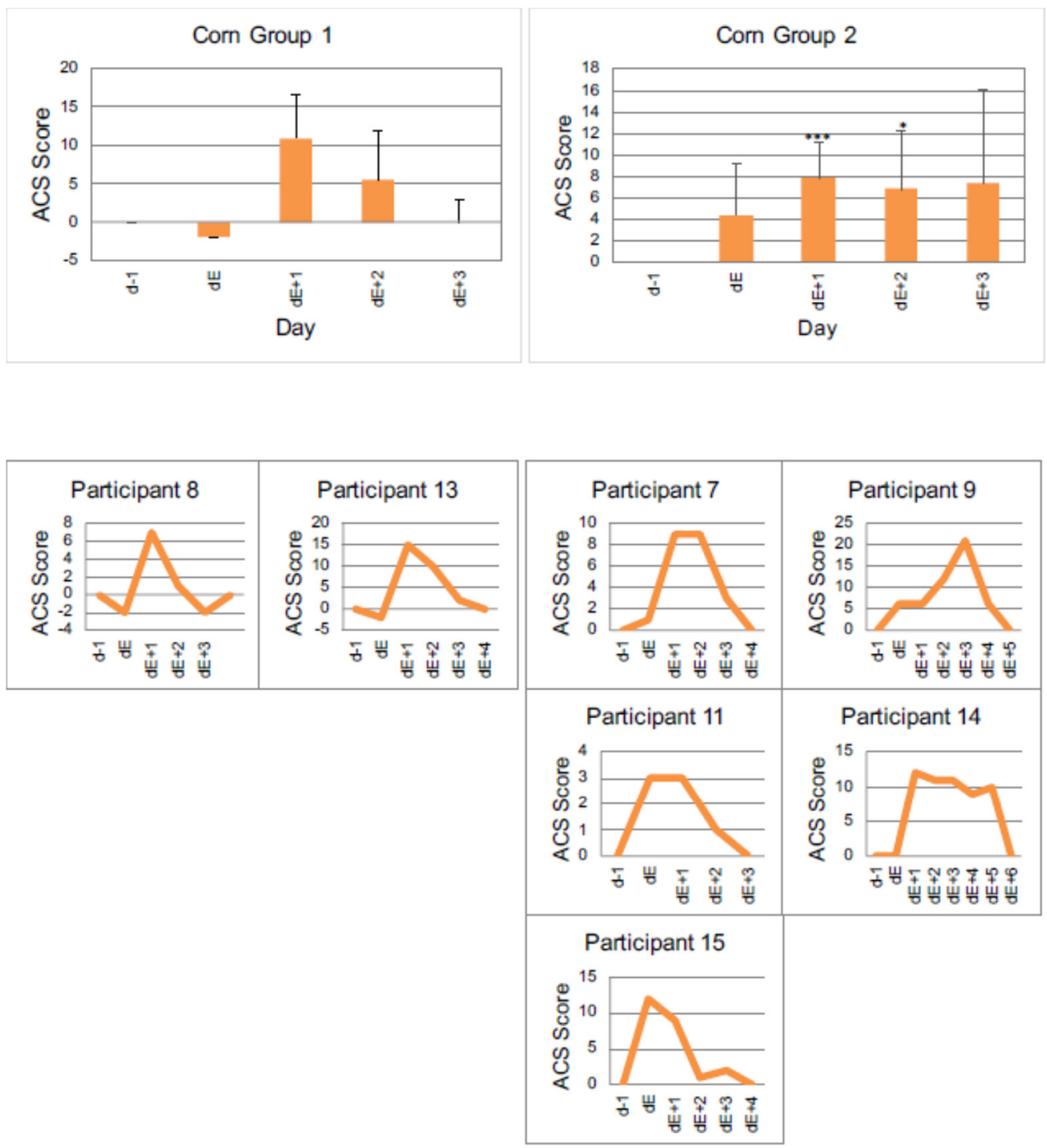

Figure 5. Individual reactions of participants to corn, measured by ACS. Group 1 (participants with a decrease of value in ACS on the day of reintroduction), vs. Group 2 (participants with an increase of value in ACS at the day of reintroduction) $p<0.05^{*}, p<0.001^{* * *}$ (one-sided $t$-test). $\mathrm{dE}-1$ : day before reintroduction, dE: day of reintroduction, $\mathrm{dE}+1$ : day 1 after reintroduction etc. 
Table 5. Means and standard deviations of intolerance reactions to corn of Group $1(n=2)$.

\begin{tabular}{ccc}
\hline Day & M & SD \\
\hline$d E$ & -2.0 & 0 \\
$\mathrm{dE}+1$ & 11.0 & 5.66 \\
$\mathrm{dE}+2$ & 5.5 & 6.36 \\
$\mathrm{dE}+3$ & 0 & 2.83 \\
\hline
\end{tabular}

Table 6. Means and standard deviations of behavioral reactions to corn of Group $2(n=5)$.

\begin{tabular}{ccccc}
\hline Day & M & SD & $\boldsymbol{t ( 4 )}$ & $\boldsymbol{p}$ \\
\hline $\mathrm{dE}$ & 4.40 & 4.83 & 2.04 & 0.111 \\
$\mathrm{dE}+1$ & 7.80 & 3.42 & 5.10 & 0.007 \\
$\mathrm{dE}+2$ & 6.80 & 5.40 & 2.81 & 0.048 \\
$\mathrm{dE}+3$ & 7.40 & 8.68 & 1.91 & 0.129 \\
\hline
\end{tabular}

\subsubsection{Example 3: Grain}

Figure 6, and Table 7 show the intolerance reaction to grain.
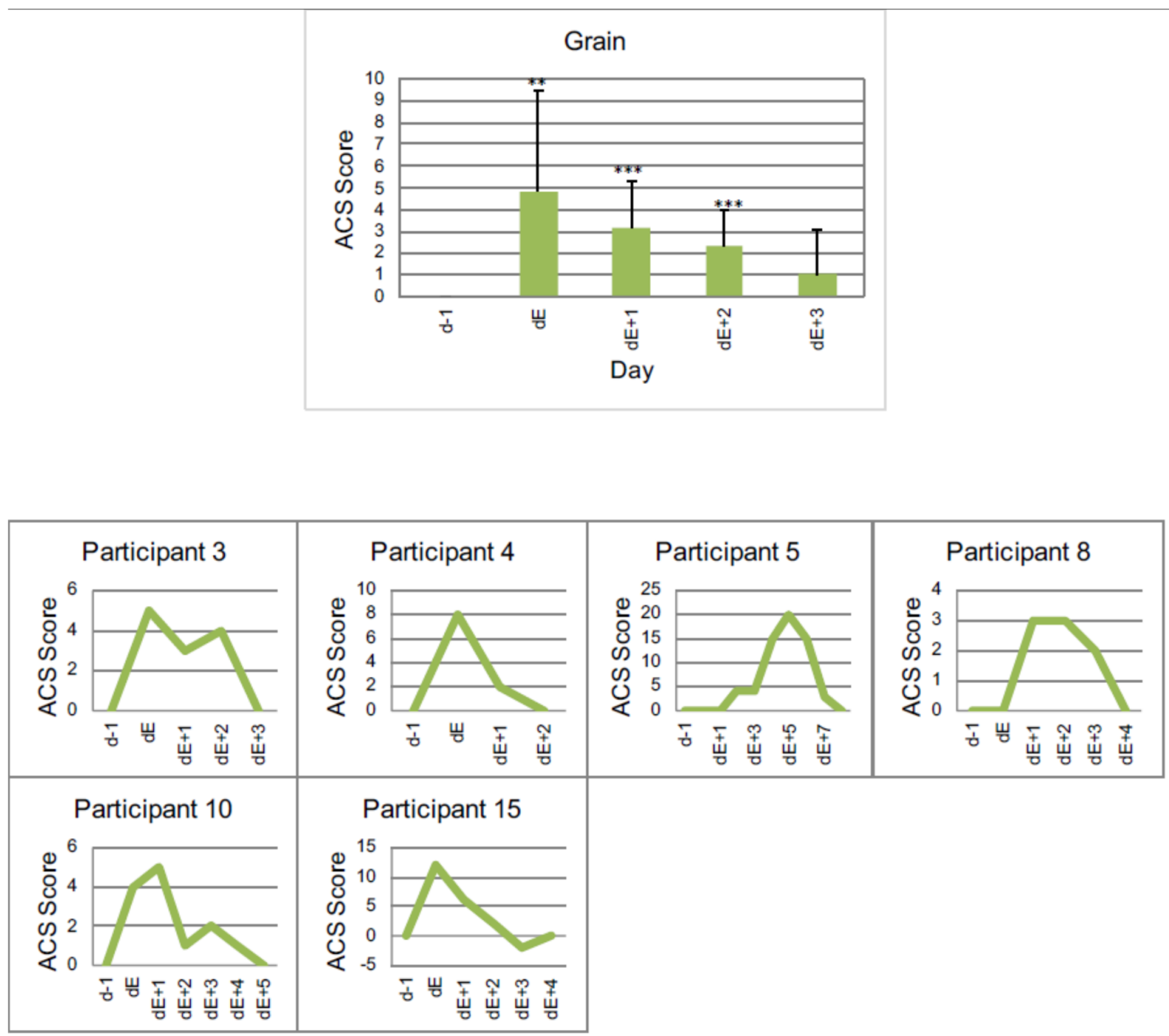

Figure 6. Individual reactions of participants to grain (including oats, wheat and other grain containing gluten) measured by ACS, $p<0.01^{* *}, p<0.001^{* * *}$ (one-sided $t$-test). $\mathrm{dE}-1$ : day before reintroduction, $\mathrm{dE}$ : day of reintroduction, $\mathrm{dE}+1$ : day 1 after reintroduction etc. 
Table 7. Means and standard deviations of behavioral reactions to grain $(n=6)$.

\begin{tabular}{ccccc}
\hline Day & M & SD & $\boldsymbol{t}(5)$ & $p$ \\
\hline $\mathrm{dE}$ & 4.83 & 4.67 & 2.54 & 0.052 \\
$\mathrm{dE}+1$ & 3.17 & 2.14 & 3.63 & 0.015 \\
$\mathrm{dE}+2$ & 2.33 & 1.63 & 3.50 & 0.017 \\
$\mathrm{dE}+3$ & 1.00 & 2.10 & 1.17 & 0.296 \\
\hline
\end{tabular}

For a total of six children (37.5\%) the symptoms worsen when eating grain. These include oats, wheat and other grains containing gluten. Corn was excluded.

\subsection{Behavioral Reactions to Intolerant Foods before Starting the OD}

In the pre-diet phase, 13 out of 16 children consumed several of the observed sensitive foods at the same time. Because of the overlap with the incompatible foods, a reliable prognosis is difficult. In three subjects incompatibilities were observed individually and without overlapping with one another. This was due to the fact that they only reacted to one incompatibility each.

One child showed an increase and decrease in ACS according to the course of the week, so that ACS increased at the weekend without a change in diet (Figure 7A). Overall, none of the children's behavior disturbances can be attributed to a clear food sensitive reaction just on the basis of the data from the pre-diet phase. Two illustrative examples are shown in Figure 7A,B. Figure 7A shows the food sensitivity of one subject before starting the diet. Food sensitivity was safely detected during the reintroduction phase: to milk, cocoa, peanut and corn. Out of four intolerant foods, three were consumed at different timepoints in the pre-diet phase as shown below.

Looking at the individual foods, milk shows an average decrease in ACS within the first $24 \mathrm{~h}$ after consuming by -1.67 . In the following days there is an increase in ACS compared to the value before the intake $(<24 \mathrm{~h}=-0.67 ; 24-48 \mathrm{~h}=+0.67 ; 48-72 \mathrm{~h}=+1)$.

When cocoa is consumed, an immediate increase in ACS is only notable on day 10 $(+2)$. On day 13 there is a delayed increase the next day $(+1)$. The remaining days (day 3 , day 6-8) are inconspicuous, with an average increase of 0.5 in the first $24 \mathrm{~h}(<24 \mathrm{~h}=0.5$; $24-48 \mathrm{~h}=-0.5 ; 48-72 \mathrm{~h}=-0.5)$.

Corn was consumed only in small amounts. On day 4 , most corn was consumed in the form of popcorn, with a delayed increase of ACS the next day $(+3) .(<24 \mathrm{~h}=-0.67$; $24-48 \mathrm{~h}=+1 ; 48-72 \mathrm{~h}=-2$ ).

Due to the weak fluctuations, no clear statement is possible. Overall, possible changes in ADHD symptoms due to intolerant foods overlap, which makes a reliable prognosis of individual food sensitivity almost impossible.

Figure 7B shows the reactions of another participant. Food sensitivities safely detected during the reintroduction phase were to bell pepper and wheat. Wheat was supplied daily in the form of baked goods (bread). On average, there was a mean decrease in ACS in the days after ingestion compared to the initial value $(<24 \mathrm{~h}=-0.75 ; 24-48 \mathrm{~h}=0$; $48-72 \mathrm{~h}=-0.75)$.

Bell peppers were eaten as spice powder (day 3 ) or raw (day 12). There is a small increase in ACS (+2) on the respective days, but day 12 , when raw paprika was eaten, is particularly noteworthy with an increase from +3 to $15(<24 \mathrm{~h}=+2 ; 24-48 \mathrm{~h}=0 ; 48$ $72 \mathrm{~h}=+0.5$ ).

It is also noticeable that on days with physical activity (soccer training, swimming training) ACS is relatively low (day 1,2,5) or decreased compared to the previous day (day 8). One reason for an increase in ACS could be that subject in 7B had a friend visiting him on day 6 and a birthday party on day 7 .

The overlay of food makes a reliable prognosis difficult. In addition, there are fluctuations that may be related to special events in everyday life, which makes it difficult to identify possibly ADHD-promoting foods. 


\section{(A)}

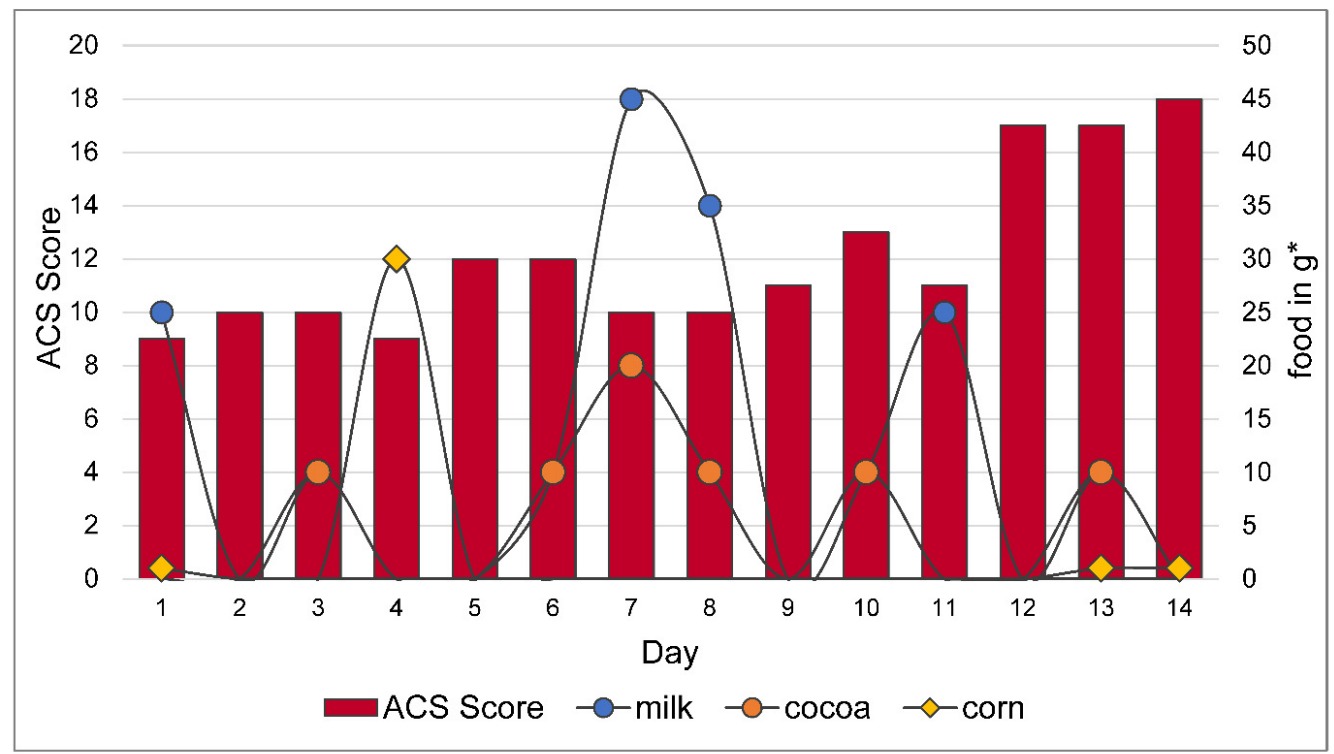

(B)

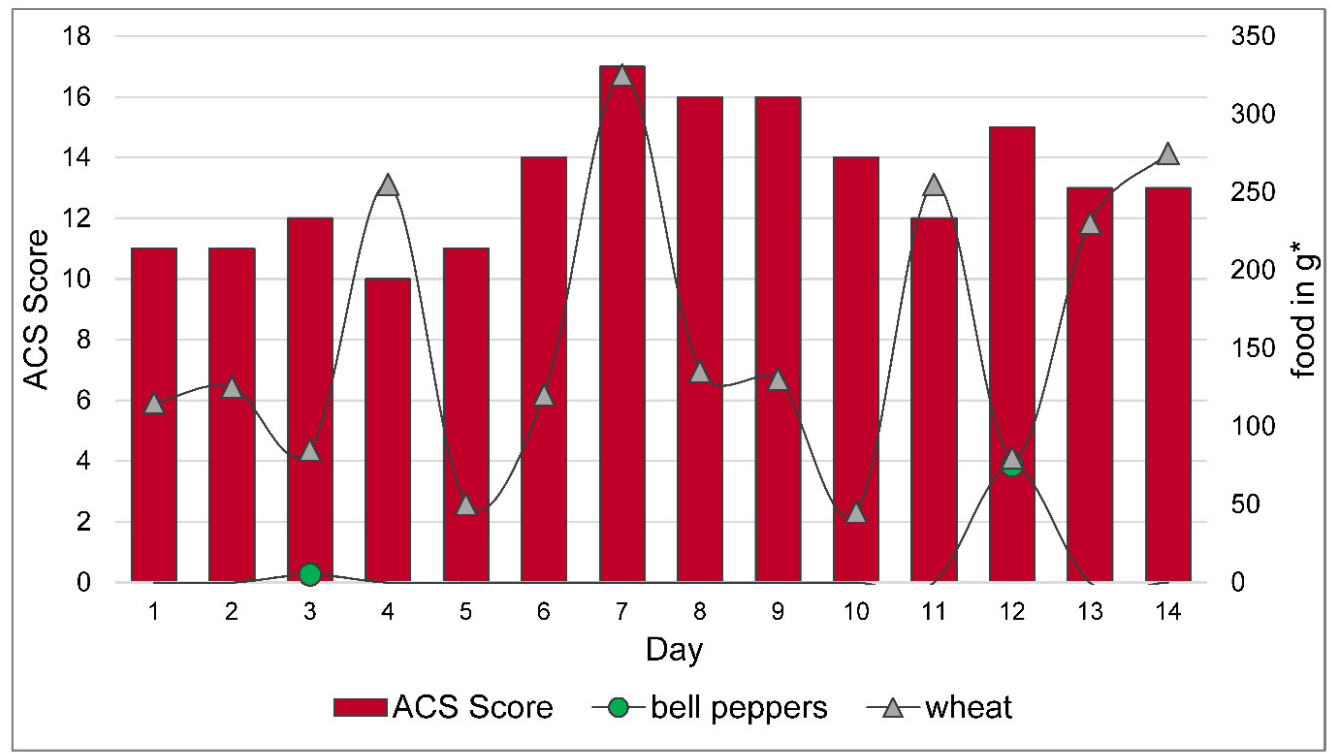

Figure 7. (A) Food sensitivity of participant 1. Reactions to different foods in the pre-diet phase. Food sensitivities safely detected during the reintroduction phase: milk, cocoa, peanut and corn. Peanuts are not mentioned because they were not eaten in the pre-diet phase. (B) Food sensitivity of participant 2. Reactions to different foods in the pre-diet phase. Food sensitivities safely detected during the reintroduction phase: bell peppers and wheat. ACS value declared by parents, displayed in red bars on the left axis. Amount of intolerable food consumed in grams * shown in lines on the right axis. * estimated amount.

\subsection{Anamnestic Intolerance Prior to OD and Observed Sensitivity during Food Reintroduction}

In an initial anamnesis, the children were asked about their eating habits. In addition to "likes" and "dislikes," they were also asked about suspected sensitivity as a possible trigger of ADHD. Of the 16 subjects, eleven (68.8\%) did not match the information in the anamnesis questionnaire with the sensitivities found later. Of the 16 subjects, there is a match between a favorite food (eggs) and a sensitivity only in one participant $(6.25 \%)$. One 
presented (6.25\%) a correspondence of a dislike (fish) with an incompatible food. In three of the 16 subjects $(18.75 \%)$ the suspicion was confirmed. The questionable foods are milk (2) and soy (1). In all three participants, physical symptoms in addition to ADHD symptoms occurred after consuming these foods.

\section{Discussion}

A main aspect of the study is to show that OD is a useful method to find out if there are food related changes of ADHD symptoms in children. Furthermore, our study is the first to investigate the individual behavioral responses on different foods related to ADHD symptoms.

Pelsser recommends that a change in diet should be considered in all children with ADHD, as Pelsser's study showed a significant effect in children with ADHD and ODD of the elimination diet. This requires medical supervision and parental cooperation when following this restrictive elimination diet [14]. In a previous study we could also show the positive effects of OD in children with ADHD [22].

Before starting the diet, it is not obvious if children react to food, and when they do so, what kind of foodstuff result in an increase of ADHD symptoms. Children included in this study did react after 4 weeks of diet. The participants showed individual food sensitivity concerning type of food, intensity or pattern of reactivity. In all patients, ADHD symptoms were intensified by various foods during the food challenge after OD.

After detecting food related ADHD symptoms by OD, it is important to find out, by reintroduction, to what kind of food the children are sensitive. In our small sample we could demonstrate 27 different foods which increased the symptoms of ADHD in our participants.

Comparing this study with previous studies on the OD by Egger et al., a concordance of frequency of intolerance more often regarding milk products can be shown. Cow's milk sensitivity occurred in $64 \%$ of the cases in Egger and Carter, in $60 \%$ of the cases in Hiedl, and in our current study in $68 \%$ of the cases. From this, one can conclude that the most common food intolerance that leads to an increase in ADHD symptoms is cow's milk. However, not all of the food sensitive children did react to milk, so there should never be a general recommendation to avoid milk in the context of ADHD. In all four studies, wheat and grains in general could be detected as common provoking foods. Egg was also more often on the list of intolerant foods in all studies. [11,13,14,16,37,38], but only individual dietary recommendations should be given in the context of the individually detected food sensitivity.

The study also shows that almost every participant experienced an increase of far more than two points in ACS after the food challenge. The amount and type of reaction were individually different. The strongest reaction was seen in one subject after taking paprika. There was an immediate increase in ADHD symptoms by 25 points as measured by ACS.

It could not be shown that a connection between certain foods and behavior can already be established during the pre-diet phase by evaluating the food and behavior diary. The pre-diet phase should, however, continue to be at the forefront when carrying out an OD to observe usual eating habits and to train the protocoling. It is also useful to have a pre-diet control protocol in order to test whether the change in daily life when focusing on nutrition and behavior of the child does influence ADHD symptoms or not.

An OD with subsequent reintroduction can be the most useful diagnostic tool to identify individual food sensitivity in connection with ADHD. Because every participant reacted very individually to different foods, there must be an individual dietary recommendations for each individual child.

Several possible different pathomechanisms are noted to cause an increase in symptoms. Most children (70\%) reacted to milk products. Of these, $73 \%$ did not react to dairy products which were free of lactose. This leads to a hypothesis that the pathomechanism of lactose intolerance could be connected to ADHD symptoms. In a previous study from 
Edreffy et al. [39], the differences in oligosaccharide metabolism between ADHD and healthy controls were described. This study supports the hypothesis that carbohydrate metabolism differs in ADHD subjects compared to control. Alabaf et al. [40] investigated physical health in children with a neurodevelopmental disorder on the basis of the database of The Children and Adolescent Twin Study in Sweden (CATSS). Their results showed that children 9-12 years of age diagnosed with ADHD suffered more than twice as often from lactose intolerance as the age-matched total population. The occurrence of celiac disease was also described to be higher in patients with ADHD. The prevalence of celiac disease increased significantly in patients with ADHD and comorbidity such as autism spectrum disorder and learning disorder.

We found ADHD related symptoms worsening in children after the consumption of different grains. This could indicate probable digestive problems in the context of different grains. Niederhofer et al. [41] reported an overrepresentation of celiac disease, identified by measuring the celiac specific antibodies anti-gliadine and anti-endomysium in patients with ADHD. Ten out of 67 patients with ADHD were diagnosed with celiac disease. A significant improvement of ADHD symptoms under gluten-free diet was observed by patients and parents. In our study, we also found remission of ADHD symptoms in grain sensitive children after three days of grain-elimination during the food reintroduction.

"Brain-gut axis" and "microbiome" have also been shown to be related to mental disorders [42,43]. Though the microbiome in humans shows a high interpersonal variation, its composition is influenced by geography, culture, and diet [44,45]. The type of nutrition plays a decisive role in the composition of the microbiome. Despite the evidence that abnormal development of the intestinal microbiome has long-term implications on host health, the causal contributions of abnormal intestinal microbiome variations to disease states have yet to be elucidated [45].

One can therefore consider whether there is a complicated mechanism behind ADHD symptoms in relation to food intake. The microbiome can be regarded as a trigger or amplifier of ADHD symptoms [43]. Kumperscak et al. found improvements in children's behavior after three months probiotic treatment with "Lactobacillus rhamnosus" [46]. A randomized controlled trial published in 2016 showed a significant improvement in ADHD symptoms in children with autism after supplementation of "Lactobacillus Plantarum PS128" [47]. These results reinforce the hypothesis of microbial influence on ADHD symptoms.

Pelsser investigated the immunological response comparing allergic and non-allergic reactions in food intolerances and food allergies in children with ADHD. IgE is implicated in typical food allergies. If reactions to foods are not mediated by IgE, the assessment of IgG levels might be useful, when considering the aim of establishing a relation between foods and ADHD. According to this theory, eating foods that induce high IgG levels would lead to a substantial behavioral relapse whereas eating foodstuff that induces low IgG levels would not. The results did not support this hypothesis [14].

This suggests that food sensitivities in ADHD are not necessarily allergic reactions. However, a cell-mediated allergic reaction has not been investigated and therefore cannot be excluded. A pilot study from Dieterich et al. [48] could identify inflammatory processes in the gut reflected in inflammation-related intolerance reactions to foods, without showing a systemic inflammation in blood parameters. Food intolerances relate to high interferon IFN- $\gamma$ concentrations in different gut regions. Gut mediated reactions to food intolerances showed differences to inflammation parameters in food allergy. In different gut regions, they found an increase of IFN- $\gamma$ which might result from an unspecific immune response to an intestinal dysbiosis in the intestine and to a release of micro-biotic peptides as described by Farin et al. [49]. This might explain our results concerning the individual reactions to intolerant foods in food reintroduction. We found different intensities of reactions and individual time-courses to recovery. This might be related to a highly individual gut microbiome and subsequently its metabolites, which can stimulate local inflammatory processes in the gut. 
This supports the theory that the composition of gut microbiome plays an important role in this context.

Whatever mechanisms a dietary intervention relies on, Stevenson et al. [50] pointed out in their research review form 2014 that a restricted elimination diet might be beneficial for ADHD symptoms in children and adults.

\section{Limitations and Future Directions}

The evaluation of the daily behavior could, besides dietary intervention, also be impacted by various factors such as social interactions or physical health.

For the assessment of ADHD symptoms, they must occur in at least two contexts (usually at home and at school). Unfortunately, teacher's ratings could not be collected in total. This is a clear limitation of the study.

The study was open, non-randomized, without a control group and without blinding the diet. Focusing on behavior and eating habits while implementing serious changes in daily life might lead to a remarkable bias in parent's ratings. To corroborate these preliminary findings, an extension of the study with a larger number of subjects would be important to confirm the effects already observed.

Children had to control their eating behavior by themselves. Whether children always provided their information on food consumption truthfully is not guaranteed. Although the importance of correct information for the diary was clearly explained, there certainly were undocumented dietary violations.

\section{Conclusions}

The European treatment guidelines on ADHD recommend that restricted elimination diets may be beneficial for children with ADHD and with a history of adverse reactions to food. However, our data indicate that there are many ADHD children without a history of adverse reaction to food that may profit from OD and subsequent identification of highly individual food sensitivity.

In summary of the available results, Oligoantigenic Diet seems to be a useful tool to identify food sensitive ADHD patients. Subsequently, detected individual food sensitivities leading to individualized dietary recommendations are useful as an additional option to the existing multimodal therapy concept.

Author Contributions: E.Y., L.B., N.B., C.C., H.-W.C., C.F. contributed to the literature search, E.Y., L.B., N.B., K.S.-M., H.-W.C., R.R., E.S., C.C., C.F. to the methodology, E.Y., L.B., N.B., H.-W.C., R.R., E.S., C.C., C.F. the interpretation of the data and E.Y., L.B., N.B., H.-W.C., R.R., E.S., C.C., C.F. to the writing of the manuscript. All authors had full access to the data. All authors have read and agreed to the published version of the manuscript.

Funding: This research received no external funding.

Institutional Review Board Statement: The study was approved by the local ethics committee (application number 111/14) in accordance with the World Medical Association's Declaration of Helsinki.

Informed Consent Statement: Informed consent and assent were obtained for all participants involved in the study.

Data Availability Statement: The data are not publicly available according to description of confidentiality and data sharing procedures described in the study's informed consent and assent documents.

Conflicts of Interest: The authors declare no conflict of interest.

\section{References}

1. Polanczyk, G.; de Lima, M.S.; Horta, B.L.; Biederman, J.; Rohde, L.A. The Worldwide Prevalence of ADHD: A Systematic Re-view and Metaregression Analysis. Am. J. Psychiatry 2007, 164, 942-948. [CrossRef]

2. Sayal, K.; Prasad, V.; Daley, D.; Ford, T.; Coghill, D. ADHD in Children and Young People: Prevalence, Care Pathways, and Service Provision. Lancet Psychiatry 2018, 5, 175-186. [CrossRef] 
3. Taylor, E.; Sergeant, J.; Asherson, P.; Banaschewski, T.; Buitelaar, J.; Coghill, D.; Danckaerts, M.; Rothenberger, A.; Sonuga-Barke, E.; Steinhausen, H.-C.; et al. European Clinical Guidelines for Hyperkinetic Disorder ? First Upgrade. Eur. Child Adolesc. Psychiatry 2004, 13, i7-i30. [CrossRef]

4. Faraone, S.V.; Perlis, R.H.; Doyle, A.E.; Smoller, J.W.; Goralnick, J.J.; Holmgren, M.A.; Sklar, P. Molecular Genetics of AttentionDeficit/Hyperactivity Disorder. Biol. Psychiatry 2005, 57, 1313-1323. [CrossRef] [PubMed]

5. Khan, S.A.; Faraone, S.V. The Genetics of ADHD: A Literature Review of 2005. Curr. Psychiatry Rep. 2006, 8, 393-397. [CrossRef] [PubMed]

6. Gillis, J.J.; Gilger, J.W.; Pennington, B.F.; DeFries, J.C. Attention Deficit Disorder in Reading-Disabled Twins: Evidence for Ge-netic Etiology. J. Abnorm. Child Psychol. 1992, 20, 303-315. [CrossRef]

7. Sonuga-Barke, E.J.; Brandeis, D.; Cortese, S.; Daley, D.; Ferrin, M.; Holtmann, M.; Stevenson, J.; Danckaerts, M.; Van Der Oord, S.; Döpfner, M.; et al. Nonpharmacological Interventions for ADHD: Systematic Review and Meta-Analyses of Randomized Controlled Trials of Dietary and Psychological Treatments. Am. J. Psychiatry 2013, 170, 275-289. [CrossRef]

8. American Academy of Pediatrics. Wolraich ML, Hagan JF, Allan C, et al; Subcommittee on Children and Adolescents with Attention-Deficit/Hyperactive Disorder. Clinical Practice Guideline for the Diagnosis, Evaluation, and Treatment of AttentionDeficit/Hyperactivity Disorder in Children and Adolescents. Pediatrics 2020, 145, e20193997. [CrossRef]

9. Sharma, A.; Couture, J. A Review of the Pathophysiology, Etiology, and Treatment of Attention-Deficit Hyperactivity Disorder (ADHD). Ann. Pharmacother. 2014, 48, 209-225. [CrossRef] [PubMed]

10. Shannon, W.R. Neuropathic Manifestations in Infants and Children as a Result of Anaphylactic Reaction to Foods Contained in Their Dietary. Arch. Pediatr. Adolesc. Med. 1922, 24, 89-94. [CrossRef]

11. Egger, J.; Graham, P.; Carter, C.; Gumley, D.; Soothill, J. Controlled Trial of Oligoantigenic Treatment in the HYPERKINETIC SYNDROME. Lancet 1985, 325, 540-545. [CrossRef]

12. Pelsser, L.; Frankena, K.; Toorman, J.; Savelkoul, H.F.J.; Pereira, R.R.; Buitelaar, J.K. A Randomised Controlled Trial into the Effects of Food on ADHD. Eur. Child Adolesc. Psychiatry 2008, 18, 12-19. [CrossRef] [PubMed]

13. Pelsser, L.M.; Frankena, K.; Buitelaar, J.K.; Rommelse, N.N. Effects of Food on Physical and Sleep Complaints in Children with ADHD: A Randomised Controlled Pilot Study. Eur. J. Nucl. Med. Mol. Imaging 2010, 169, 1129-1138. [CrossRef] [PubMed]

14. Pelsser, L.; Frankena, K.; Toorman, J.; Savelkoul, H.F.; Dubois, E.A.; Pereira, R.R.; Haagen, A.T.; Rommelse, N.N.; Buitelaar, J.K. Effects of a Restricted Elimination Diet on the Behaviour of Children with Attention-Deficit Hyperactivity Disorder (INCA study): A Randomised Controlled Trial. Lancet 2011, 377, 494-503. [CrossRef]

15. Kaplan, B.J.; McNicol, J.; Conte, A.R.; Moghadam, H.K. Dietary replacement in preschool-aged hyperactive boys. Pediatrics 1989, 83, 7-17. [PubMed]

16. Carter, C.M.; Urbanowicz, M.; Hemsley, R.; Mantilla, L.; Strobel, S.; Graham, P.J.; Taylor, E. Effects of a Few Food Diet in Attention Deficit Disorder. Arch. Dis. Child. 1993, 69, 564-568. [CrossRef]

17. McCann, D.; Barrett, A.; Cooper, A.; Crumpler, D.; Dalen, L.; Grimshaw, K.; Kitchin, E.; Lok, K.Y.-W.; Porteous, L.; Prince, E.; et al. Food Additives and Hyperactive Behaviour in 3-Year-Old and 8/9-Year-Old Children in the Community: A Randomised, Double-Blinded, Placebo-Controlled Trial. Lancet 2007, 370, 1560-1567. [CrossRef]

18. Boris, M.; Mandel, F.S. Foods and Additives are Common Causes of the Attention Deficit Hyperactive Disorder in Children. Ann. Allergy 1994, 72, 462-468.

19. Rytter, M.J.H.; Andersen, L.B.B.; Houmann, T.; Bilenberg, N.; Hvolby, A.; Mølgaard, C.; Michaelsen, K.F.; Lauritzen, L. Diet in the Treatment of ADHD in Children-A Systematic Review of the Literature. Nord. J. Psychiatry 2014, 69, 1-18. [CrossRef]

20. Hill, P. Current Topic: An Auditable Protocol for Treating Attention Deficit/Hyperactivity Disorder. Arch. Dis. Child. 2001, 84, 404-409. [CrossRef]

21. Pelsser, L.; Frankena, K.; Toorman, J.; Pereira, R.R. Diet and ADHD, Reviewing the Evidence: A Systematic Review of MetaAnalyses of Double-Blind Placebo-Controlled Trials Evaluating the Efficacy of Diet Interventions on the Behavior of Children with ADHD. PLoS ONE 2017, 12, e0169277. [CrossRef] [PubMed]

22. Dölp, A.; Schneider-Momm, K.; Heiser, P.; Clement, C.; Rauh, R.; Clement, H.-W.; Schulz, E.; Fleischhaker, C. Oligoantigenic Diet Improves Children's ADHD Rating Scale Scores Reliably in Added Video-Rating. Front. Psychiatry 2020, 11, 730. [CrossRef]

23. Chambers, W.J.; Puig-Antich, J.; Hirsch, M.; Paez, P.; Ambrosini, P.J.; Tabrizi, M.A.; Davies, M. The Assessment of Affective Dis-Orders in Children and Adolescents by Semistructured Interview. Test-Retest Reliability of the Schedule for Affective Disorders and Schizophrenia for School-Age Children, Present Episode Version. Arch. Gen. Psychiatry 1985, 42, 696-702. [CrossRef] [PubMed]

24. Dupaul, G.J. Parent and Teacher Ratings of ADHD Symptoms: Psychometric Properties in a Community-Based Sample. J. Clin. Child Psychol. 1991, 20, 245-253. [CrossRef]

25. Dupaul, G.J.; Reid, R.; Anastopoulos, A.D.; Lambert, M.C.; Watkins, M.W.; Power, T.J. Parent and Teacher Ratings of AttentionDeficit/Hyperactivity Disorder Symptoms: Factor Structure and Normative Data. Psychol. Assess. 2016, 28, 214-225. [CrossRef] 
26. Anastopoulos, A.D.; Beal, K.K.; Reid, R.J.; Reid, R.; Power, T.J.; Dupaul, G.J. Impact of Child and Informant Gender on Parent and Teacher Ratings of Attention-Deficit/Hyperactivity Disorder. Psychol. Assess. 2018, 30, 1390-1394. [CrossRef]

27. Storebø, O.J.; Ramstad, E.; Krogh, H.B.; Nilausen, T.D.; Skoog, M.; Holmskov, M.; Rosendal, S.; Groth, C.; Magnusson, F.L.; Moreira-Maia, C.R.; et al. Methylphenidate for Children and Adolescents with Attention Deficit Hyperactivity Disorder (ADHD). Cochrane Database Syst. Rev. 2015, CD009885. [CrossRef] [PubMed]

28. Mercier, C.; Roche, S.; Gaillard, S.; Kassai, B.; Arzimanoglou, A.; Herbillon, V.; Roy, P.; Rheims, S. Partial Validation of a French Version of the ADHD-Rating Scale IV on a French Population of Children with ADHD and Epilepsy. Factorial Structure, Reliability, and Responsiveness. Epilepsy Behav. 2016, 58, 1-6. [CrossRef]

29. Zhang, S.; Faries, D.; Vowles, M.; Michelson, D. ADHD Rating Scale IV: Psychometric Properties from a Multinational Study as Clinician-Administered Instrument. Int. J. Methods Psychiatr. Res. 2005, 14, 186-201. [CrossRef]

30. Alexandre, J.L.; Lange, A.-M.; Bilenberg, N.; Gorrissen, A.M.; Søbye, N.; Lambek, R. The ADHD Rating Scale-IV Preschool Version: Factor Structure, Reliability, Validity, and Standardisation in a Danish Community Sample. Res. Dev. Disabil. 2018, 78, 125-135. [CrossRef]

31. Richarte, V.; Corrales, M.; Pozuelo, M.; Serra-Pla, J.; Ibáñez, P.; Calvo, E.; Corominas, M.; Bosch, R.; Casas, M.; Ramos-Quiroga, J.A. Spanish Validation of the Adult Attention Deficit/Hyperactivity Disorder Rating Scale (ADHD-RS): Relevance of clinical subtypes. Rev. Psiquiatr. Salud Ment. 2017, 10, 185-191. [CrossRef]

32. Wittchen, H.-U.; Zaudig, M.; Fydrich, T. SKID Strukturiertes Klinisches Interview für DSM-IV. Achse I und II. Göttingen: Hogrefe. Zeitschrift für klinische Psychologie und Psychotherapie. 1999. Available online: https:/ / econtent.hogrefe.com/doi/10.1026//0 084-5345.28.1.68 (accessed on 27 July 2021).

33. DuPaul, G.J.; Power, T.J.; Anastopoulos, A.D.; Reid, R. ADHD Rating Scale—IV: Checklists, Norms, and Clinical Interpretation; Guilford Press: New York, NY, USA, 1998; pp. 1-80.

34. Conners, C.K.; Goyette, C.H.; Southwick, D.A.; Lees, J.M.; Andrulonis, P.A. Food additives and hyperkinesis: A controlled double-blind experiment. Pediatrics 1976, 58, 154-166.

35. Koerner, U.; Schareina, A. Nahrungsmittelallergien und -Unverträglichkeiten. In Diagnostik, Therapie und Beratung; Haug: Stuttgart, Germany, 2010.

36. Lidzba, K.; Christiansen, H.; Drechsler, R. Conners 3: Conners Skalen zur Aufmerksamkeit und Verhalten-3: Deutschsprachige Adaptation der Conners 3rd Edition (Conners 3) von C. Keith Conners: Manual (K. Conners, Hrsg.); Hans Huber: Bern, Switzerland, 2013.

37. Pelsser, L.M.; Van Steijn, D.J.; Frankena, K.; Toorman, J.; Buitelaar, J.K.; Rommelse, N.N. A Randomized Controlled Pilot Study into the Effects of a Restricted Elimination Diet on Family Structure in Families with ADHD and ODD. Child. Adolesc. Ment. Health 2012, 18, 39-45. [CrossRef] [PubMed]

38. Hiedl, S. Duodenale VIP-Rezeptoren in der Dünndarmmukosa bei Kindern mit Nahrungsmittelinduziertem Hyperkinetischen Syndrom. Zur Erlangung des Medizinischen Doktorgrades; Ludwig-Maximillians-Universität München: München, Germany, 2004.

39. Endreffy, I.; Bjørklund, G.; Urbina, M.A.; Chirumbolo, S.; Doşa, M.D.; Dicső, F. High Levels of Glycosaminoglycans in the Urines of Children with Attention-Deficit/Hyperactivity Disorder (ADHD). J. Mol. Neurosci. 2020, 70, 1018-1025. [CrossRef] [PubMed]

40. Alabaf, S.; Gillberg, C.; Lundström, S.; Lichtenstein, P.; Kerekes, N.; Rastam, M.; Anckarsäter, H. Physical Health in Children with Neurodevelopmental Disorders. J. Autism Dev. Disord. 2019, 49, 83-95. [CrossRef]

41. Niederhofer, H. Association of Attention-Deficit/Hyperactivity Disorder and Celiac Disease: A Brief Report. Prim. Care Companion CNS Disord. 2011, 13, e1-e3. [CrossRef] [PubMed]

42. Aarts, E.; Ederveen, T.; Naaijen, J.; Zwiers, M.P.; Boekhorst, J.; Timmerman, H.M.; Smeekens, S.P.; Netea, M.G.; Buitelaar, J.K.; Franke, B.; et al. Gut Microbiome in ADHD and Its Relation to Neural Reward Anticipation. PLoS ONE 2017, 12, e0183509. [CrossRef]

43. Hiergeist, A.; Gessner, J.; Gessner, A. Current Limitations for the Assessment of the Role of the Gut Microbiome for Attention Deficit Hyperactivitiy Disorder (ADHD). Front. Psychiatry 2020, 11, 623. [CrossRef]

44. Schink, M.; Konturek, P.C.; Tietz, E.; Dieterich, W.; Pinzer, T.C.; Wirtz, S.; Neurath, M.F.; Zopf, Y. Microbial Patterns in Patients with Histamine Intolerance. J. Physiol. Pharmacol. 2018, 69, 579-593.

45. Barko, P.; McMichael, M.; Swanson, K.; Williams, D. The Gastrointestinal Microbiome: A Review. J. Vet. Intern. Med. 2017, 32, 9-25. [CrossRef] [PubMed]

46. Kumperscak, H.G.; Gricar, A.; Ülen, I.; Micetic-Turk, D. A Pilot Randomized Control Trial with the Probiotic Strain Lactobacillus rhamnosus GG (LGG) in ADHD: Children and Adolescents Report Better Health-Related Quality of Life. Front. Psychiatry 2020, 11, 181. [CrossRef] [PubMed]

47. Liu, Y.-W.; Liong, M.T.; Chung, Y.-C.E.; Huang, H.-Y.; Peng, W.-S.; Cheng, Y.-F.; Lin, Y.-S.; Wu, Y.-Y.; Tsai, Y.-C. Effects of Lactobacillus Plantarum PS128 on Children with Autism Spectrum Disorder in Taiwan: A Randomized, Double-Blind, PlaceboControlled Trial. Nutrients 2019, 11, 820. [CrossRef] [PubMed]

48. Dieterich, W.; Tietz, E.; Kohl, M.; Konturek, P.C.; Rath, T.; Neurath, M.F.; Zopf, Y. Food Intolerance of Unknown Origin: Caused by Mucosal Inflammation? A Pilot Study. Clin. Transl. Gastroenterol. 2021, 12, e00312. [CrossRef] 
49. Farin, H.F.; Karthaus, W.R.; Kujala, P.; Rakhshandehroo, M.; Schwank, G.; Vries, R.G.; Kalkhoven, E.; Nieuwenhuis, E.E.; Clevers, H. Paneth Cell Extrusion and Release of Antimicrobial Products is Directly Controlled by Immune Cell-Derived IFN- $\gamma$. J. Exp. Med. 2014, 211, 1393-1405. [CrossRef] [PubMed]

50. Stevenson, J.; Buitelaar, J.; Cortese, S.; Ferrin, M.; Konofal, Éric; Lecendreux, M.; Simonoff, E.; Wong, I.C.K.; Sonuga-Barke, E.; The European ADHD Guidelines Group. Research Review: The Role of Diet in the Treatment of Attention-Deficit/Hyperactivity Disorder-An Appraisal of the Evidence on Efficacy and Recommendations on the Design of Future Studies. J. Child. Psychol. Psychiatry 2014, 55, 416-427. [CrossRef] [PubMed] 